The author reported no conflicts of interest.

The Journal policy requires editors and reviewers to disclose conflicts of interest and to decline handling or reviewing manuscripts for which they may have a conflict of interest. The editors and reviewers of this article have no conflicts of interest.

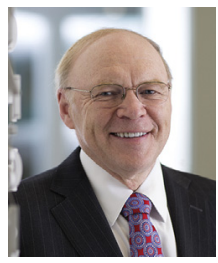

\section{REPLY: FOR CONNECTIVE DISEASE ROOT ANEURYSMS, REIMPLANTATION IS THE BEST OPTION \\ Reply to the Editor:}

Jahanyar and colleagues ${ }^{1}$ conclude that upon late follow-up, the remodeling operation is prone to fail in patients with Marfan syndrome, but the reimplantation operation holds up better. We agree and came to the same conclusion a number of years $\mathrm{ago}^{2}$; as a result, we stopped using the remodeling operation for Marfan patients, except for bicuspid valve patients with large roots (a rare occurrence). Similar to what the authors describe, we saw either failures from dilation at the annular suture or in the intercommissure angle.

While the reimplantation operation has proved durable in our initial series of 178 connective tissue disease patientsmostly with Marfan patients-in a more recent analysis of 212 patients with no operative deaths, the durability of our modified method of reimplantation appears even better, with approximately $97 \%$ freedom from reoperation at
10 years. $^{3}$ It should be noted that we do not use gel impregnated DePaulis Valsalva grafts, although my father-in-law, as vice president, oversaw the development of gel impregnated grafts at Coats in Glasgow. The enlarged root is useful for biological composite grafts, where the hope is that for later transcatheter aortic valve replacement procedures, the coronary ostia are farther away and less likely to get obstructed. Of note is the report from Beckmann and colleagues ${ }^{4}$ that the DePaulis grafts may dilate the root over time, resulting in an increased risk of aortic valve regurgitation-a problem we have seen and had to reoperate for in patients from other institutions. This will require careful long-term follow-up.

Lars G. Svensson, $M D, P h D$ Heart, Vascular, and Thoracic Institute Cleveland Clinic Cleveland, Ohio

\section{References}

1. Jahanyar J, de Kerchove L, Munoz DE, el Khoury G. Twenty-year follow-up after valve-sparing aortic root replacement with the Yacoub or David procedure in Marfan patients. J Thorac Cardiovasc Surg Open. 2021;7:47-9.

2. Svensson LG, Blackstone EH, Feng J, de Oliveira D, Gillinov AM, Thamilarasan M, et al. Are Marfan syndrome and marfanoid patients distinguishable on long-term follow-up? Ann Thorac Surg. 2007;83:1067-74.

3. Svensson LG, Blackstone EH, Alsalihi M, Batizy LH, Roselli EE, McCullough R, et al. Midterm results of David reimplantation in patients with connective tissue disorder. Ann Thorac Surg. 2013;95:555-62.

4. Beckmann E, Leone A, Martens A, Mariani C, Krueger H, Cebotari S, et al. Comparison of two strategies for aortic valve-sparing root replacement. Ann Thorac Surg. 2020;109:505-11.

https://doi.org/10.1016/j.xjon.2021.08.004 